\title{
Microstructure of Dental Amalgams Containing High and Low Copper Contents
}

\author{
MANohar L. Malhotra and Kamal Asgar \\ School of Dentistry, The University of Michigan, Ann Arbor, Michigan 48109, USA
}

\begin{abstract}
Microstructure of commercial dental alloys and their a malgams were studied primarily by $x$-ray diffraction, optical metallography, scanning electron microscopy, and $x$-ray energy dispersive spectroscopy. $X$-ray diffraction revealed more phases than normally reported in these materials. Presence of new phases was discussed and their formation mechanism understood. Some phases having interacting $2 \theta^{\circ}$ values with others were properly identified. Both new and conventional dental alloys and their amalgams, namely Tytin, Sybraloy, Dispersalloy, Kerr Spheraloy, Caulk Spherical, Shofu Spherical, and Caulk 20th Century Microcut were used to complete the investigation.
\end{abstract}

\section{J Dent Res 56(12): 1481-1487, December 1977.}

Dental alloy containing mostly silver and tin with some copper when reacted with mercury produced an amalgam which has been widely accepted as a restorative material for filling cavities. The simplified setting reaction has been mentioned as:

$$
\begin{gathered}
\gamma(\mathrm{Ag}, \mathrm{Sn}, \mathrm{Cu})+\mathrm{Hg} \rightarrow \gamma_{1}\left(\mathrm{Ag}_{2} \mathrm{Hg}_{3}\right) \\
+\gamma_{2}\left(\mathrm{Sn}_{7-8} \mathrm{Hg}\right)+\mathrm{Cu}_{6} \mathrm{Sn}_{5} \\
+\gamma(\mathrm{Ag}, \mathrm{Sn}, \mathrm{Cu}) \text { unreacted particles. }
\end{gathered}
$$

In fact, the commercial dental alloy was not a single-phase alloy and contained more than one phase. This multiphase alloy on reaction with mercury produced an amalgam, a complicated material consisting of more than the abovelisted phases. The goal of the present investigation was to systematically determine the microstructure in both original dental alloys and their corresponding amalgams. This was achieved using the modern technology of $x$-ray diffrac-

Received for publication Autust 30, 1976

Accepted for publication tebruary $22,1977$.

This investigation was presented in part at the $541 \mathrm{~h}$ general meeting of the IADR, Miami Bcach, Florida, March 1976.

This research was completely supported by a postdoctoral award to one of the authors (Dr. M. L. Malhotra) from the National Institute of Demal Research, National Institutes of Healih, under Research Grant \# 5 F 32 DE-05029-02, Bethesda, Md. tion, optical and/or electron optical methods, and $\mathrm{x}$-ray energy dispersive spectroscopy.

\section{Experimental Procedures}

Materials AND PREPARATION. - Table l shows the brand of the selected alloys, their manufacturers, batch numbers, mercury-to-alloy ratio, mechanical amalgamators used, trituration times, and the weights of the pestle in the specified capsules. Table 2 shows the approximate chemical composition and shape of these alloy particles. Cylindrical amalgam specimens were prepared following the parameters in Table 1 along with the ADA testing procedures. ${ }^{1}$ The specimens were allowed to set at 37 $\pm 0.1 \mathrm{C}$ for about one month prior to microstructure determination.

X-RAY DIFFRACTION ANALYSIS. - Both original alloys and their amalgam powders were analyzed separately using $x$-ray diffraction techniques. The $x$-ray machine used was a Phillip's (XRG-3000) x-ray generator with copper $K_{\alpha}$ radiation $(\lambda=1.54 \AA$ ) and a nickel filter. In order to obtain an accurate value for $2 \theta^{\circ}$, the diffractometer scanning speed was adjusted to $l^{\circ}$ per minute. The $\mathrm{x}$-ray signal was recorded on a chart recorder calibrated for 1 inch equivalent to $1^{\circ}$. The $2 \theta^{\circ}$ values obtained from the diffraction peaks were converted into $d$-spacings $(\AA)$ using ASTM conversion tables.

Polishing AND ETCHING TECHNIQUes. - A room temperature curing epoxy resin was used to mount specimens for polishing. The surface was rough polished first with four grades of emery papers; the finest grade was $4 / 0$. Final polishing was achieved by using in order, $15 \mu \mathrm{m}$, $1 \mu \mathrm{m}$, and $0.05 \mu \mathrm{m}$ dispersion alumina powder on a slowly revolving brass polishing lap covered with a billiard polishing cloth. The specimens were then washed thoroughly with distilled water and dried.

The polished specimens were etched by a chemical etchant developed by Allan et al. ${ }^{2}$ When chemical solutions were used in order as 
TABLE 1.

SELECTED DENTAL ALLOYS

\begin{tabular}{|c|c|c|c|c|c|c|}
\hline Dental Alloy & Mariufacturer & $\begin{array}{l}\text { Batch } \\
\text { Number }\end{array}$ & $\begin{array}{l}\text { Mercury t } \\
\text { Alloy } \\
\text { Ratio } \\
(\%)\end{array}$ & $\begin{array}{c}\text { Amalgamator } \\
\text { Used }\end{array}$ & $\begin{array}{l}\text { Trituration } \\
\text { Time } \\
\text { (Sec) }\end{array}$ & $\begin{array}{l}\text { Weight of } \\
\text { Pestle (gm) }\end{array}$ \\
\hline $\begin{array}{l}\text { Tytin } \\
\text { (predispensed) }\end{array}$ & $\begin{array}{l}\text { S.S. White } \\
\text { Philadelphia, PA }\end{array}$ & 17511 & 43.0 & Capmaster & 6 & $\cdots$ \\
\hline $\begin{array}{l}\text { Sybraloy } \\
\text { (predispensed) }\end{array}$ & $\begin{array}{l}\text { Kerr Mfg. Co. } \\
\text { Romulus, MI }\end{array}$ & 1009751277 & 46.0 & $\begin{array}{c}\text { Caulk } \\
\text { Vari-Mix II } \\
\text { (M-2 setting) }\end{array}$ & 10 & 0.206 \\
\hline $\begin{array}{l}\text { Dispersalloy } \\
\text { (predispensed) }\end{array}$ & $\begin{array}{l}\text { Johnson \& } \\
\text { Johnson } \\
\text { East Windsor, NJ }\end{array}$ & $\begin{array}{c}\text { HRI } \\
8137.002841\end{array}$ & 50.0 & $\begin{array}{c}\text { Caulk } \\
\text { Vari-Mix II } \\
\text { (M-2 setting) }\end{array}$ & 12 & 0.689 \\
\hline $\begin{array}{l}\text { Kerr Spheraloy } \\
\text { (predispensed) }\end{array}$ & $\begin{array}{l}\text { Kerr Mfg. Co. } \\
\text { Romulus, MI }\end{array}$ & 0805753169 & 48.5 & Wig-L-Bug & 20 & 0.185 \\
\hline $\begin{array}{l}\text { Caulk Spherical } \\
\text { (pellet) }\end{array}$ & $\begin{array}{l}\text { L. D. Caulk Co. } \\
\text { Milford, DE }\end{array}$ & $1264 \cdot 601010$ & 46.2 & Wig-L.Bug & 20 & 0.594 \\
\hline $\begin{array}{l}\text { Shofu spherical } \\
\text { (powder) }\end{array}$ & $\begin{array}{l}\text { Shofu Dental } \\
\text { Corp., Menlo } \\
\text { Park, CA. }\end{array}$ & 297501 & 48.0 & Wig-L-Bug & 12 & 1.066 \\
\hline $\begin{array}{l}\text { Caulk 20th } \\
\text { Century Micro- } \\
\text { cut (powder) }\end{array}$ & $\begin{array}{l}\text { L. D. Caulk Co. } \\
\text { Milford, DE }\end{array}$ & $8 \mathrm{~J} 68$ & 53.7 & $\begin{array}{c}\text { Caulk } \\
\text { Vari-Mix II } \\
\text { (M-2 setting) }\end{array}$ & 14 & 0.594 \\
\hline
\end{tabular}

All specimens were tested according 10 A.D.A. Specification.

TABLE 2.

Approximate Chemical Composition of Dental Alloys

\begin{tabular}{|c|c|c|c|c|}
\hline & & jor Eleme & & \\
\hline Alloy & $\underset{(\%)}{\mathrm{Ag}}$ & $\underset{(\%)}{\mathrm{Sn}}$ & $\begin{array}{c}\mathrm{Cu} \\
(\%)\end{array}$ & Particie Shape \\
\hline Tytin & 60 & 27 & 13 & sphere \\
\hline Sybraloy & 40 & 30 & 30 & sphere \\
\hline Dispersalloy & 72 & 0 & 28 & sphere \\
\hline & $68-70$ & $26-28$ & $2 \cdot 4$ & $\begin{array}{l}\text { (1/3 proportion) } \\
\text { irregular } \\
\text { (2/3 proportion) }\end{array}$ \\
\hline Kerr Spheraloy & $68-70$ & $26-28$ & 2.4 & sphere \\
\hline Caulk Spherical & $68-70$ & $26-28$ & 2.4 & sphere \\
\hline Shofu Spherical & $68-70$ & $26-28$ & $2-4$ & sphere \\
\hline $\begin{array}{l}\text { Caulk 20th Cen- } \\
\text { tury Microcut }\end{array}$ & 68.70 & $26 \cdot 28$ & $2-4$ & irregular \\
\hline
\end{tabular}

* Some alloys contain $\leq 1 \%$ zinc. However zinc does not play any role in the microstructure determination of these alloys or in their corresponding amaigams and, therefore, is ignored. 


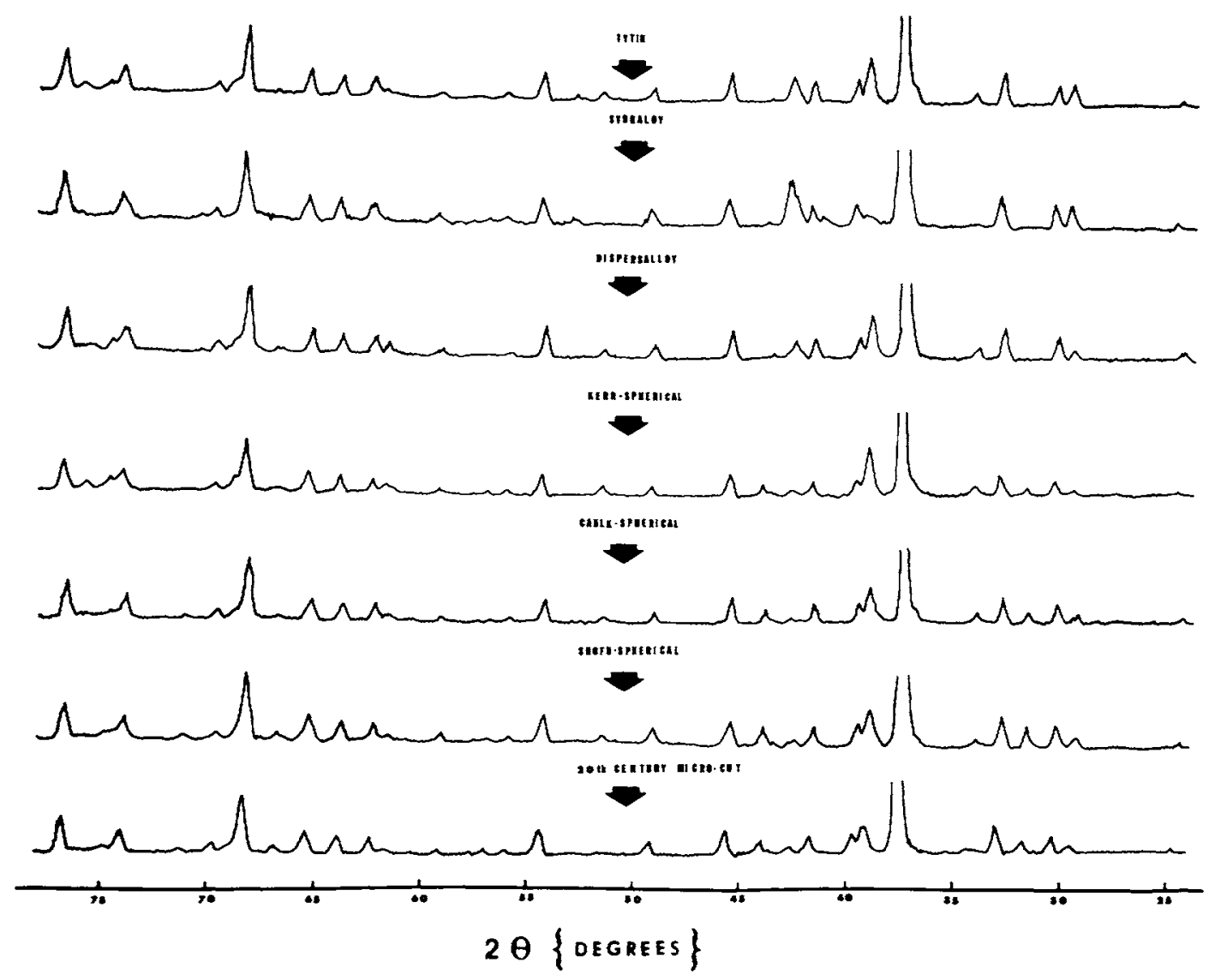

Frg 1. - X-ray diffraction patterns obtained from amalgams.

described by the authors, the specimen surface revealed all the required phases in dental amal. gam.

METALlograpHIC EXAMINATION. - The polished and etched specimens were examined on a Leitz Metallurgical microscope. Microstructure features were also obtained in the scanning electron microscope (Jeol Inc., JSMU3). A Kevex Si (Li) x-ray energy dispersive spectrometer attached to the SEM was used to obtain $x$-ray energy spectra from the different elements present on the polished specimen surface. Identification of these elements qualitatively defined the presence of known phases on the specimen surface.

\section{Results}

Table 3 shows $x$-ray diffraction data obtained from original alloy powders. The $2 \theta^{\circ}$ values obtained from the diffraction peaks, their relative intensities, and the identified phases with corresponding hkl indices are listed in the table. Figure 1 shows the complete $x$-ray diffraction patterns obtained from these amalgams. The phase analysis of these patterns is given in Table 4. Figure 2 shows the part of $x$ ray diffraction pattern over the important range of $2 \Theta^{\circ}$ values for $\gamma_{2}$ peaks for all amalgams studied.

Figure 3 shows an optical photomicrograph of a Shofu amalgam surface after being polished and etched by the procedures outlined in the previous section. Figure $4(\mathrm{a})$ shows a scanning electron photomicrograph of a typical enlarged area of a polished surface of Shofu amalgam. The areas marked " $C$ " in Figure 4(a) were subjected to $\mathrm{x}$-ray elemental analysis using the energy dispersive spectrometer, and the observed $\mathrm{x}$-ray energy spectrum is shown in Figure $4(\mathrm{~b})$. 


\section{Discussion}

Prior to indexing of complicated diffraction patterns for amalgams containing multiple phases such as $\gamma, \gamma_{1}, \gamma_{2}, \mathrm{Cu}_{3} \mathrm{Sn}, \mathrm{Cu}_{6} \mathrm{Sn}_{5}, \mathrm{Ag}$ and/or $\mathrm{Cu}$, it was decided to index relatively simple diffraction patterns from the original alloys containing $\gamma,(\mathrm{Cu}-\mathrm{Sn}), \mathrm{Ag}$ and/or $\mathrm{Cu}$ phases. This helped considerably in the further determination of microstructure in amalgams.

Table 3 shows a complete $x$-ray diffraction analysis of these selected original alloy powders. Most reactive element tin was completely utilized in forming $\gamma$ and $\mathrm{Cu}_{3} \mathrm{Sn}$ phases. Presence of $\mathrm{Ag}$ and/or $\mathrm{Cu}$ elements, which was obvious for Dispersalloy containing ( $\mathrm{Ag}-\mathrm{Cu}$ ) eutectic phase, was never reported for other spherical alloys. These elements in small amounts might precipitate because of fast cooling rates produced in the atomization process.

Also, it was observed that Sybraloy containing $30 \% \mathrm{Cu}$ and $30 \% \mathrm{Sn}$ (Table 2) showed $\mathrm{Cu}_{6} \mathrm{Sn}_{5}$ phase which might be attributed to the high concentration of $\mathrm{Cu}$ and $\mathrm{Sn}$ elements present in this original alloy powder.

Figure I shows the complete $\mathrm{x}$-ray diffraction patterns obtained from these amalgams. The phase analysis is given in Table 4 . The unreacted $\gamma$ and $\mathrm{Cu}_{3} \mathrm{Sn}$ phases resulted from the original alloys. The $\gamma_{1}$ phase resulted from the two different reactions; (1) the reaction of mercury

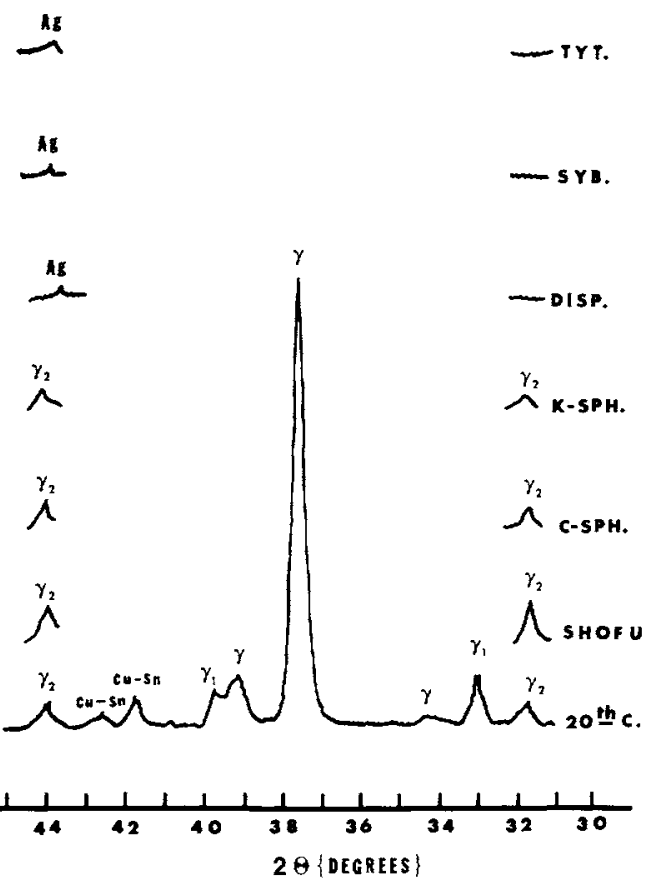

FIG 2. - Part of $x$-ray diffraction pattern over the range of $2 \theta^{\circ}$ values for $\gamma_{2}$ peaks in amalgams.

with silver part of $\mathrm{Ag}_{9} \mathrm{Sn}(\gamma)$ phase and (2) the reaction of mercury with the silver element that

TABLE 3 .

X-RAy Diffraction ANalysis of Alloy POWDERS

\begin{tabular}{|c|c|c|c|c|c|c|c|c|}
\hline $\begin{array}{l}\text { Tytin } \\
2 \theta^{\circ}\end{array}$ & $\begin{array}{l}\text { Sybra. } \\
20^{\circ}\end{array}$ & $\begin{array}{l}\text { Disp. } \\
20^{\circ}\end{array}$ & $\begin{array}{l}\text { K-Sph. } \\
2 \theta^{\circ}\end{array}$ & $\begin{array}{l}\text { C.Sph. } \\
2 \theta^{\circ}\end{array}$ & $\begin{array}{l}\text { S-Sph. } \\
2 \theta^{\circ}\end{array}$ & $\begin{array}{l}20 \mathrm{~h} \\
\text { Cent. } \\
2 \theta^{\circ}\end{array}$ & $\begin{array}{c}\text { Possible } \\
\text { hkl }\end{array}$ & $\begin{array}{l}\text { Probable } \\
\text { hk! }\end{array}$ \\
\hline- & $31.6^{w}$ & - & - & - & - . & - & $\mathrm{Cu}_{6} \mathrm{Sn}_{5}(101)$ & $\mathrm{Cu}_{6} \mathrm{Sn}_{5}(101)$ \\
\hline $34.0^{M}$ & $33.9^{M}$ & $34.0^{M}$ & $33.7^{M}$ & $34.5^{M}$ & $34.4^{M}$ & $34.3^{M}$ & $\gamma(020,110)$ & $\gamma(020,110)$ \\
\hline $36.9^{M}$ & $36.8^{M}$ & $37.0^{M}$ & $36.7^{M}$ & $37.5^{M}$ & $37.2^{M}$ & $37.3^{M}$ & $\gamma(002)$ & $\gamma(002)$ \\
\hline- & - & $37.6^{s t}$ & - & $37.9^{M}$ & $-\cdot$ & --- & $\mathrm{Ag}(111)$ & Ag (111) \\
\hline $38.9^{s}$ & $38.8^{5}$ & $39.0^{s}$ & $38.7^{s}$ & $39.5^{s}$ & $39.4^{5}$ & $39.3^{s}$ & $\gamma(021,111)$ & $\gamma(021,111)$ \\
\hline $40.9^{W}$ & $40.8^{M}$ & -- & -- & - & - & $41.2^{w}$ & $\mathrm{Cu}_{3} \mathrm{Sn}(-)$ & $\mathrm{Cu}_{3} \mathrm{Sn}(-)$ \\
\hline $42.5^{M}$ & $42.4^{s}$ & $42.5^{M}$ & $42.3^{w}$ & $42.9^{w}$ & $42.6^{w}$ & $42.9^{w}$ & $\left.\begin{array}{c}\mathrm{Cu}(111) \\
\mathrm{Cu}_{3} \mathrm{Sn}(-) \\
\mathrm{Cu}_{6} \mathrm{Sn}_{5}(102,110)\end{array}\right\}$ & $\left.\begin{array}{c}\mathrm{Cu}(111) \\
\mathrm{Cu}{ }_{3} \operatorname{Sn}(-)\end{array}\right\}$ \\
\hline$\ldots$ & - & $43.8^{M}$ & $43.0^{w}$ & $44.0^{w}$ & - & $\cdots$ & $\operatorname{Ag}(200)$ & $\operatorname{Ag}(200)$ \\
\hline $51.4^{M}$ & $51.3^{M}$ & $51.5^{M}$ & $51.2^{M}$ & $51.9^{M}$ & $51.9^{m}$ & $51.8^{M}$ & $\gamma(022,112)$ & $\gamma(022,112)$ \\
\hline $56.6^{w}$ & $56.5^{M}$ & - & $-\cdots$ & - & & - & $\left.\begin{array}{c}\mathrm{Cu}_{3} \mathrm{Sn}(--) \\
\mathrm{Cu}_{6} \mathrm{Sn}_{5}(112)\end{array}\right\}$ & $\mathrm{Cu}_{3} \mathrm{Sn}(-)$ \\
\hline $61.6^{M}$ & $61.6^{M}$ & $61.6^{m}$ & $61.3^{M}$ & $62.0^{M}$ & $61.9^{s}$ & $61.9^{M}$ & $\left.\begin{array}{c}\gamma(130,200) \\
\mathrm{Cu}_{5} \operatorname{Sn}_{5}(103,202)\end{array}\right\}$ & $\gamma(130,200)$ \\
\hline$\cdots$ &.. & $64.0^{\text {tr }}$ & $63.0^{\mathrm{W}}$ & $64.3^{w}$ & - & & $\mathrm{Ag}(220)$ & $\operatorname{Ag}(220)$ \\
\hline
\end{tabular}

Letters $S, M$, or $W(S-$ srong, $M-m e d i u m, W-W e a k)$ on $2 \theta^{\circ}$-values denote relative intersity of diftraction peaks. hkl values for Cu, Sn are not listed in ASTM iables. 
was detected in the original alloys. During amalgamation, a large portion of $\mathrm{Cu}_{3} \mathrm{Sn}$ phase from the original alloys containing this phase was converted into $\mathrm{Cu}_{6} \mathrm{Sn}_{5}$ phase. ${ }^{3}$ This conversion of phases helped in a reduction of $\gamma_{2}$ phase in amalgams. Also, some diffraction peaks corresponding to other phases had $2 \theta^{\circ}$ values which were close to the $2 \theta^{\circ}$ values of $\gamma_{2}$ phase. To resolve this ambiguity, it was necessary to redraw part of the $\mathrm{x}$-ray diffraction pattern over the range of $2 \theta^{\circ}$ values for $\gamma_{2}$ peaks for all amalgams as shown in Figure 2. The following information was obtained from this figure:

(1) There were two diffraction peaks for $\gamma_{2}$ phase in the range of $2 \theta^{\circ}$ values shown. It was found from standard tables that the diffraction peak for $\gamma_{2}$ phase at $2 \Theta \sim 31.8^{\circ}$ had higher intensity than the peak for $\gamma_{2}$ phase at $2 \Theta \sim$ $44.0^{\circ}$. The results indicated that Kerr Spheraloy, Caulk Spherical, Shofu Spherical, and Caulk 20th Century Microcut amalgams, classified as conventional amalgams, had both $\gamma_{2}$ peaks with intensities as expected. For Tytin, Sybraloy, and Dispersalloy amalgams, classified as new amalgams, the intense diffraction peak for $\gamma_{2}$ phase at $2 \theta \sim 31.8^{\circ}$ was missing. A new weak diffraction peak at $2 \Theta \sim 43.8^{\circ}$ appeared in these amalgams. This new diffraction peak at $2 \Theta \sim 43.8^{\circ}$ was close to the diffraction peak for $\gamma_{2}$ phase at $2 \Theta \sim 44.0^{\circ}$. This might

TABLE 4.

$\mathrm{X}$-Ray Diffraction ANalysis of Amalgams

\begin{tabular}{|c|c|c|c|c|c|c|c|c|c|}
\hline $\begin{array}{l}\text { Tytin } \\
2 \theta^{\circ}\end{array}$ & $\begin{array}{c}\text { Sybra. } \\
2 \theta^{\circ}\end{array}$ & $\begin{array}{l}\text { Disp. } \\
2 \theta^{\circ}\end{array}$ & $\begin{array}{c}\text { K-Sph. } \\
2 \theta^{\circ}\end{array}$ & $\begin{array}{c}\text { C-Sph: } \\
2 \theta^{\circ}\end{array}$ & $\begin{array}{l}\text { S-Sph. } \\
2 \theta^{\circ}\end{array}$ & $\begin{array}{l}20 \mathrm{th} \\
\text { Cent. } \\
2 \theta^{\circ}\end{array}$ & $\begin{array}{c}\text { Rel. } \\
\text { Inten. }\end{array}$ & $\begin{array}{c}\text { Possible } \\
\text { hk」 }\end{array}$ & $\begin{array}{c}\text { Probable } \\
\text { hkl }\end{array}$ \\
\hline 24.6 & 24.8 & 24.4 & - & 24.5 & 24.5 & - & $W$ & $\gamma_{1}(220)$ & $\gamma_{1}(220)$ \\
\hline 29.7 & 29.7 & 29.5 & 29.7 & 29.5 & 29.3 & 29.5 & $\mathbf{M}$ & $\mathrm{Cu}_{6} \mathrm{Sn}_{5}(101)$ & $\mathrm{Cu}_{6} \mathrm{Sn}_{5}(101)$ \\
\hline 30.4 & 30.5 & 30.2 & 30.5 & 30.4 & 30.2 & 30.4 & $\mathbf{M}$ & $\gamma_{1}(222)$ & $\gamma_{1}(222)$ \\
\hline- & - & - & 31.9 & 31.8 & 31.8 & 31.8 & $\mathbf{M}$ & $\gamma_{2}(100)$ & $\gamma_{2}(100)$ \\
\hline 32.9 & 33.0 & 32.8 & 33.1 & 32.9 & 32.8 & 33.0 & $\mathbf{M}$ & $\gamma_{1}(321)$ & $\gamma_{1}(321)$ \\
\hline 34.2 & - & 34.0 & 34.3 & 34.2 & 34.0 & 34.3 & W & $\gamma(020,110)$ & $\gamma(020,110)$ \\
\hline 37.6 & 37.7 & 37.4 & 37.7 & 37.6 & 37.4 & 37.6 & $\mathrm{~S}$ & $\left.\begin{array}{c}\gamma(002) \\
\gamma(330,411) \\
A g(111)\end{array}\right\}$ & $\left.\begin{array}{c}\gamma(002) \\
\gamma_{1}(330,411)\end{array}\right\}$ \\
\hline 39.2 & 39.4 & 39.0 & 39.2 & 39.1 & 39.0 & 39.2 & M & $\gamma(021,111)$ & $\gamma(021,111)$ \\
\hline 39.8 & 39.8 & 39.5 & 39.8 & 39.6 & 39.5 & 39.7 & M & $\gamma_{1}(420)$ & $\gamma_{1}(420)$ \\
\hline 41.8 & 41.9 & 41.6 & 41.8 & 41.7 & 41.6 & 41.7 & M & $\gamma_{1}(332)$ & $\gamma_{1}(332)$ \\
\hline 42.8 & 42.8 & 42.5 & 42.8 & 42.8 & 42.6 & 42.6 & M & $\left.\begin{array}{c}\mathrm{Cu}_{3} \operatorname{Sn}(-) \\
\mathrm{Cu}(111) \\
\mathrm{Cu}_{6} \mathrm{Sn}_{5}(102,110)\end{array}\right\}$ & $\mathrm{Cu}_{6} \operatorname{Sn}_{5}(102,110)$ \\
\hline 43.9 & 43.9 & 43.6 & - & - & - & - & $W$ & $\left.\begin{array}{c}\gamma_{1}(422) \\
\operatorname{Ag}(200)\end{array}\right\}$ & $\operatorname{Ag}(200)$ \\
\hline- & - & - & 44.2 & 44.0 & 44.0 & 44.0 & $\mathbf{M}$ & $\gamma_{2}(101)$ & $\gamma_{2}(101)$ \\
\hline 45.7 & 45.7 & 45.5 & 45.7 & 45.6 & 45.5 & 45.6 & M & $\gamma_{1}(431,510)$ & $\gamma_{1}(431,510)$ \\
\hline 49.3 & 49.4 & 49.1 & 49.3 & 49.3 & 49.2 & 49.2 & W & $\gamma_{\mathrm{I}}(52 \mathrm{I})$ & $\gamma_{1}(521)$ \\
\hline 51.7 & - & 51.5 & 51.7 & 51.7 & 51.6 & - & W & $\gamma(022,112)$ & $\gamma(022,112)$ \\
\hline 52.9 & 53.0 & - & - & -- & - & - & W & $\mathrm{Cu}_{6} \mathrm{Sn}_{5}(201)$ & $\mathrm{Cu}_{6} \mathrm{Sn}_{5}(201)$ \\
\hline 54.4 & 54.5 & 54.2 & 54.5 & 54.3 & 54.3 & 54.4 & M & $\gamma_{1}(442,600)$ & $\gamma_{\mathrm{I}}(442,600)$ \\
\hline 56.2 & 56.2 & - & 56.2 & - & 55.8 & 56.0 & W & $\left.\begin{array}{l}\gamma_{1}(532,611) \\
\mathrm{Cu}_{6} \mathrm{Sn}_{5}(112)\end{array}\right\}$ & $\mathrm{Cu}_{6} \mathrm{Sn}_{5}(112)$ \\
\hline- & - & - & 57.1 & - & - & 57.0 & W & $\gamma_{2}(110)$ & $\gamma_{2}(110)$ \\
\hline- & - & - & - & - & - & 57.7 & $w$ & $\gamma_{1}(620)$ & $\gamma_{1}(620)$ \\
\hline 59.3 & 59.3 & 59.0 & 59.3 & 59.2 & 59.1 & 59.2 & W & $\left.\begin{array}{c}\gamma_{1}(541) \\
\mathrm{Cu}_{6} \operatorname{Sn}_{5}(103)\end{array}\right\}$ & $\left.\begin{array}{c}\gamma_{1}(541) \\
\mathrm{Cu}_{6} \mathrm{Sn}_{5}(103)\end{array}\right\}$ \\
\hline- & - & 61.6 & 61.8 & 61.7 & 61.5 & -- & W & $\gamma(130,200)$ & $\gamma(130,200)$ \\
\hline 62.4 & 62.3 & 62.1 & 62.4 & 62.3 & 62.1 & 62.3 & $\mathbf{M}$ & $\left.\begin{array}{c}\gamma_{1}(631) \\
\mathrm{Cu}_{6} \mathrm{Sn}_{5}(202)\end{array}\right\}$ & $\left.\begin{array}{c}\gamma_{1}(631) \\
\mathrm{Cu}_{6} \mathrm{Sn}_{5}(202)\end{array}\right\}$ \\
\hline 63.9 & 63.9 & 63.7 & 63.9 & 63.8 & 63.7 & 63.9 & $\mathbf{M}$ & $\left.\begin{array}{c}\gamma_{1}(444) \\
\mathrm{Ag}(220)\end{array}\right\}$ & $\gamma_{1}(444)$ \\
\hline 65.4 & 65.4 & 65.1 & 65.4 & 65.2 & 65.2 & 65.3 & $\mathrm{M}$ & $\left.\begin{array}{c}\gamma_{1}(543,710) \\
\gamma_{2}(111)\end{array}\right\}$ & $\gamma_{1}(543,710)$ \\
\hline
\end{tabular}

Letters $S, M$, or $W(S-$ strong, $M$-medium, $W$-weak) denole relative intensity of diffraction peaks.

hikl values for $\mathrm{CU}_{3} \mathrm{Sn}$ are not listed in ASTM tables. 


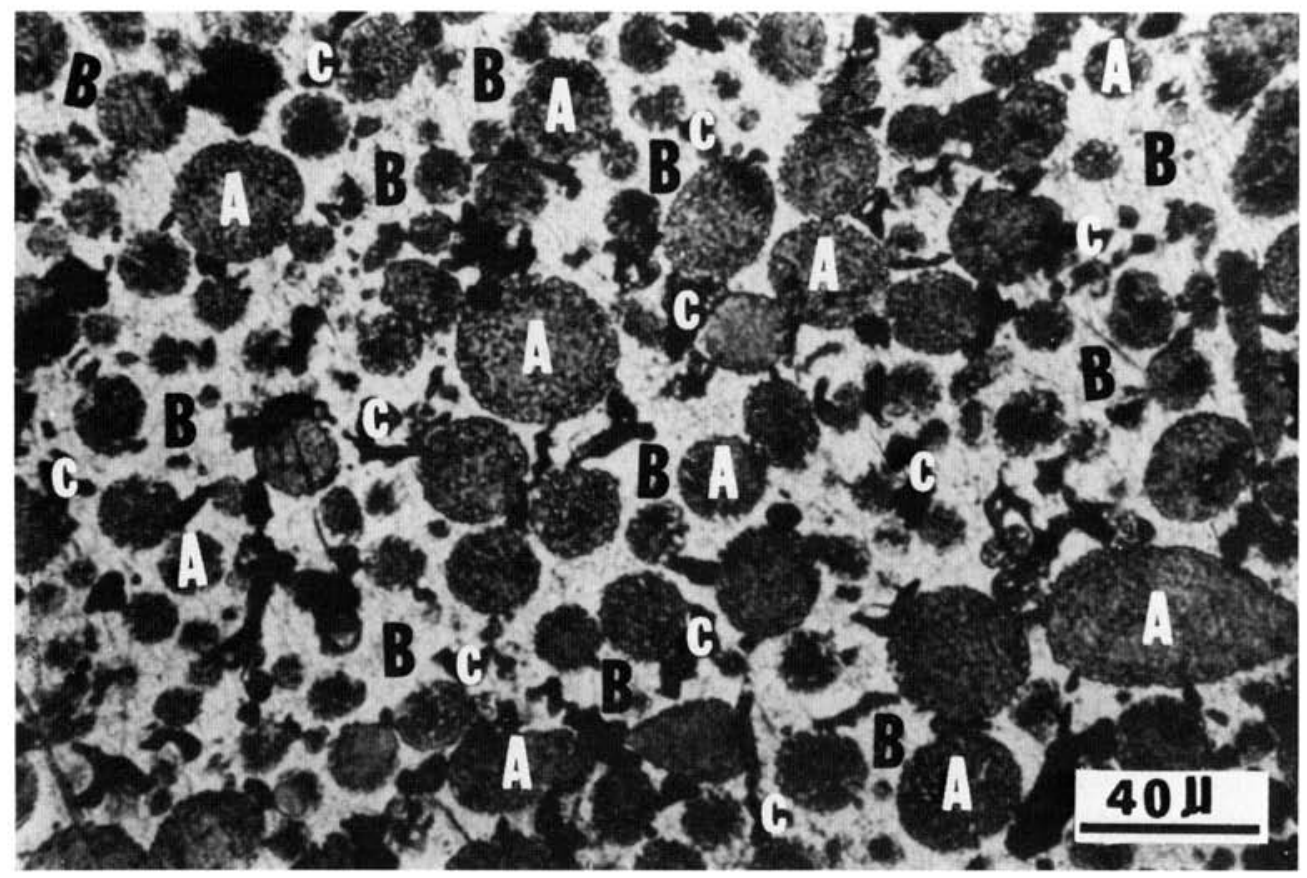

FIG 3. - A typical low magnification optical photomicrograph of a

Shofu amalgam surface after being polished and etched.

lead to a wrong conclusion that this weak diffraction peak corresponded to $\gamma_{2}$ phase. In fact, this new weak diffraction peak was identified from Ag element. Thus, Tytin, Sybraloy, and Dispersalloy amalgams had no $\gamma_{2}$ phase in their microstructure.

(2) Careful investigation of the intensities of $\gamma_{2}$ peaks indicated that Shofu amalgam had more $\gamma_{2}$ phase among the $\gamma_{2}$-containing amalgams. This amalgam also showed peculiar mechanical properties, as reported. ${ }^{4}$ This led us to further investigate this amalgam under the microscope. Figure 3 shows a low magnification optical photomicrograph of a Shofu amalgam surface after it was polished and etched according to procedures outlined earlier. The spherical particles marked " $\mathrm{A}$ " and the light matrix areas marked "B" were well-defined $\gamma$ and $\gamma_{1}$ phases. Surprisingly, the dark areas marked "C" were scattered all over the surface. The dark areas "C" could correspond to either $\gamma_{2}$ phase or porosity normally observed in amal. gams. Because of no contrast difference between $\gamma_{2}$ phase and porosity in the photomicrograph, it was then decided to determine the phase corresponding to dark " $\mathrm{C}$ " areas on the scanning electron microscope with an attached $\mathrm{x}$-ray energy dispersive spectrometer. The spec- imen surface was again polished, thoroughly washed and dried. The polished surface was examined in the scanning electron microscope. Figure 4(a) shows a high magnification scanning electron photomicrograph of typical " $\mathrm{C}$ " areas on the specimen surface to be studied for energy dispersive $\mathrm{x}$-ray analysis. Figure 4(b) shows the observed $x$-ray emission spectrum from the "C" areas of Figure 4(a). The spectrum indicated $\mathrm{x}$-ray emission peaks for $\mathrm{Al}, \mathrm{Ag}$, $\mathrm{Sn}$, and $\mathrm{Hg}$ elements. Aluminum appeared from the polishing alumina powder which was embedded in the specimen during the polishing process. Presence of weak $\mathrm{Ag}$ peak resulted from the penetration of the electron beam beneath the surface layers of the specimen. The remaining $\mathrm{Hg}$ and $\mathrm{Sn}$ elements corresponded to $(\mathrm{Sn}-\mathrm{Hg})$ phase, known as $\gamma_{2}\left(\mathrm{Sn}_{7-8} \mathrm{Hg}\right)$. This confirmed that the areas marked " $\mathrm{C}$ " in Figure 4(a), in fact, were $\gamma_{2}$ areas. Thus, Shofu amalgam had large $\gamma_{2}$ phase crystals as identified and scattered all over the surface (Fig 3 ). This was the reason that the diffraction pattern for Shofu amalgam showed intense $\gamma_{2}$ peaks comparing to other $\gamma_{2}$-containing amalgams.

\section{Conclusion}

The conclusion of the present study was made as follows: 


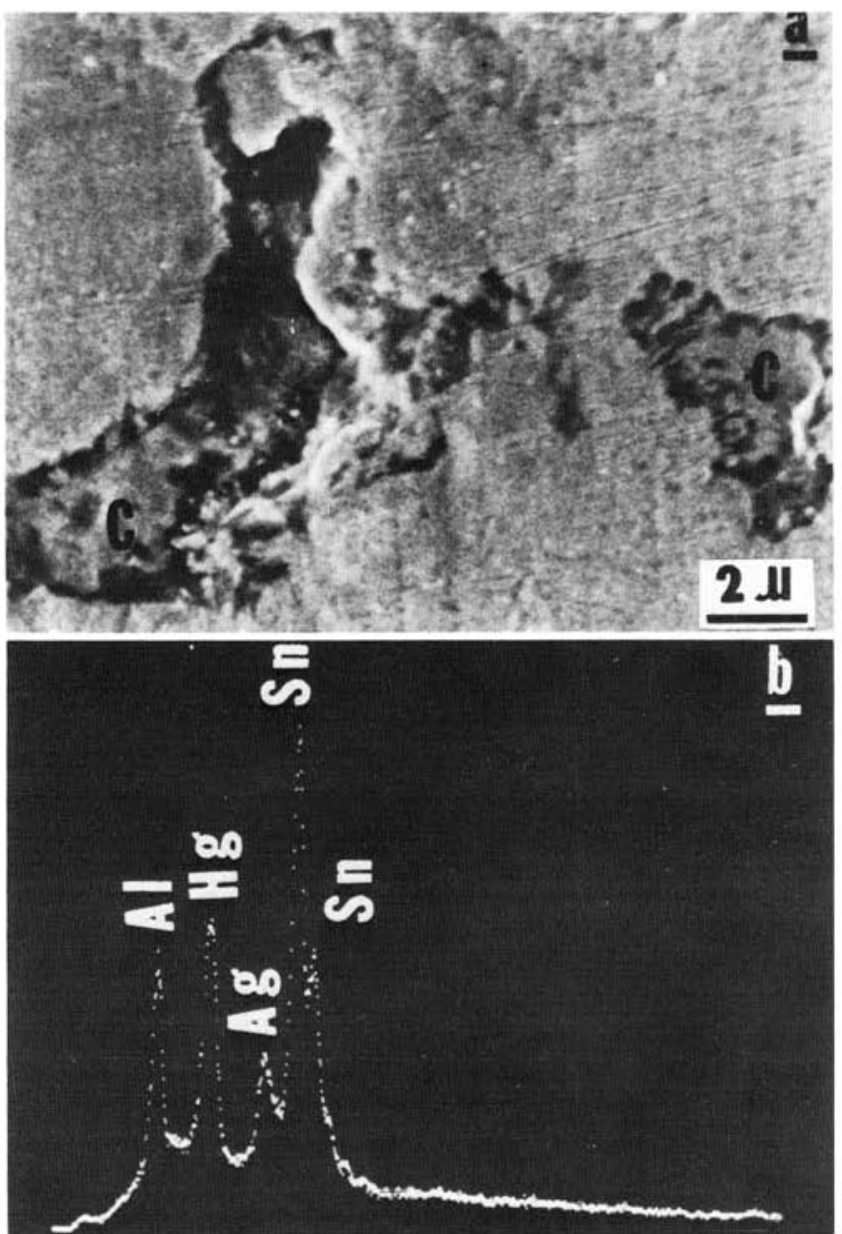

FIG 4(a). - Scanning electron photomicrograph of a polished Shofu amalgam surface; showing areas marked " $\mathrm{C}$ " to be studied for elemental analysis using energy dispersive $\mathrm{x}$-ray spectrometer.

FIG 4(b). - X-ray emission spectrum observed from areas " $\mathrm{C}$ " in Figure 4(a).

(1) The amalgam contained both unreacted phases from the original alloy and the phases produced from the reaction of mercury with the original alloy. The unreacted phases from the original alloy were separately determined and then identified in the amalgam diffraction pattern. Then an effort was made to identify the remaining phases in the amalgam produced during amalgamation process. Also, interacting $2 \theta^{\circ}$ values from different phases were carefully resolved.

(2) The silver element that was identified both in spherical alloys and their amalgams resulted from the fast cooling rates produced in atomization process.

(3) In an amalgam, the optical contrast produced for $\gamma_{2}$ and porosity was the same. Therefore, $\gamma_{2}$ phase was differentiated from porosity through the additional use of $\mathrm{x}$-ray energy dispersive spectrometer.
(4) Shofu amalgam had large $\gamma_{2}$ crystals scattered all over the specimen.

(5) The present work demonstrated that Sybraloy amalgam, similar to Tytin and Dispersalloy amalgams, was free from $\gamma_{2}$ phase.

\section{References}

1. American Dental Association, Guide to Dental Materials and Devices, 7th ed, Chicago, II, 1974-1975.

2. All.an, F. C.; Asgar, K.; and Peyton, F. A.: Microstructure of Dental Amalgam, J Dent Res 44:1002-1012, 1965.

3. Mahler, D. B.; Adey, J. D.; and Eysden, J. V.: Microprobe Analysis of a High Copper Amalgam Alloy, DMG Microfilm, IADR Meeting, Miami Beach, Fl, 1976.

4. Malhotra, M. L., and Asgar, K.: Relationship Between Microstructure, Creep and Strength in Dental Amalgam, DMG Microfilm, IADR Meeting, Miami Beach, Fl, 1976. 